\title{
Environmental Management Science Program ANNUAL PROGRESS REPORT
}

\author{
U.S. Department of Energy
}

\section{Combined Extraction of Cesium, Strontium, and Actinides from Alkaline Media : An Extension of the Caustic-Side Solvent Extraction (CSSX) Process Technology}

Principal Investigator: Lætitia H. Delmau ${ }^{1}$

Co-investigators: $\quad$ David T. Hobbs ${ }^{2}$ and Kenneth N. Raymond ${ }^{3}$

${ }^{1}$ Chemical Separations Group, Chemical Sciences Division, Oak Ridge National Laboratory, P.O. Box 2008, Bldg. 4500S, Oak Ridge, TN 37831-6119. Phone: 865-576-2093. Fax: 865-5744939. E-mail: delmaulh@ ornl.gov

${ }^{2}$ Westinghouse Savannah River Company, Savannah River Technology Center, Building 773-A, Rm. B-117, Aiken, SC 29808. Phone: 803-725-2838. Fax: 803-725-4704. E-mail: david.hobbs@srs.gov

${ }^{3}$ Department of Chemistry, University of California, Berkeley, CA 94720-1460. Phone: 510-6427219. Fax: 510-486-5283. E-mail: raymond@ socrates.berkeley.edu.

EMSP Project: $\quad$ \#81936

Project Duration: $\quad$ Oct. 1, 2001 - Sept. 30, 2004

Program Officer: $\quad$ Cindy Kendrick, Manager, Environmental Technology Programs, Oak Ridge National Laboratory, Oak Ridge, TN 37831-6119, P.O. Box 2008, Bldg. 4500S. Phone: (865) 241-6584. Fax: (865) 576-1100. E- mail: kendrickcm@ ornl.gov

Any opinions, findings, conclusions, or recommendations expressed herein are those of the authors and do not necessarily reflect the views of DOE. 


\section{Research Objective}

This fundamental research on combined cesium, strontium, and actinide separation from alkaline media by solvent extraction addresses the EM need for more efficient processes for the combined separation of these elements.

The goal of this research is to obtain fundamental information for the development of more efficient processes for the combined separation of cesium, strontium, and transuranic elements from high level waste within the U.S. Department of Energy's (U.S. DOE) complex. These improved processes are targeted primarily for treating the wastes present at the U.S. DOE's Hanford and Savannah River sites. Combined separation of the radionuclides from these wastes would permit disposal of the treated waste as low-level waste, significantly reducing the volume of high level waste. Solvent extraction using the calixarene-based CSSX process has been shown to be a very effective separation method for cesium removal from High Level Waste (HLW) present at the U.S. DOE's Savannah River Site (SRS).

The wastes present at these sites are highly alkaline and accordingly most of the actinides are in the sludge phase. However, enough actinide materials still remain in the supernatant liquid that separation will be required, followed by disposal in a geological repository. The current technologies being considered at Hanford for cesium removal (resins) and at Savannah River for strontium and actinides (monosodium titanate) could be improved, resulting in significant cost savings. Alternatives need to be presented and developed. The principal goal of this work is to extend the solvent extraction technology chosen in October 2001 by U.S. DOE to remove cesium from the SRS high level waste. It would include removal of strontium and actinides, therefore addressing the need to develop an alternative to MST that would achieve the separation of all radionuclides, possibly in one stage by combining selective ligands in the solvent. The benefits would involve a reduction in the number of operations, in the amount of secondary wastes, and in the footprint of the process. The combined extraction of cesium, strontium, and actinides is more appealing: indeed, if only cesium and strontium are removed from the high-level waste, uranium and transuranium elements would remain present in large enough quantities and the raffinate would still meet the regulatory definition of transuranic waste (TRU). If the actinides were removed along with cesium and strontium, only one stream of HLW would then be generated, and the raffinate could be disposed as Low level Waste. To remove the actinides and strontium present in the waste, new classes of ligands will be developed and tested. Extremely strong chelators capable of binding actinides in alkaline media have been developed in Berkeley based on the demonstrated complexing properties of siderophores. Synthetic analogs of catecholamides or hydroxamic acids proven to be powerful and highly specific actinide(IV) sequestering agents - the 2,3-dihydroxyterephthalamides (TAMs) and the hydroxypyridinones (HOPOs). These ligands bind to actinides with high stability constants that manifest themselves in two important ways: 1) These ligands prevent metal hydrolysis and precipitation at high $\mathrm{pH}$, and, 2) They are capable of sequestering metals that are present in low concentrations. Amido derivatives of calix[8]arenes are known to be strong and selective for strontium under acidic or neutral conditions. Testing of these materials under alkaline conditions is also one of the objectives of these studies. Ultimately, the solvent system developed for the removal of cesium, strontium, and actinides will be tested on actual waste. 


\section{Research Progress and Implications}

This report summarizes work performed during the second year of a three-year project. Three different calix[8]arene octaamides were received from the University of Parma, Italy. These calixarenes were tested for the strontium extraction performance and were found to be very effective, even for solutions containing several moles per liters of sodium. Their effectiveness over the classical crown ether dicyclohexano-18-crown-6 lies in the remarkable extraction obtained from caustic media. The entire amount of strontium extracted can be easily stripped from the solvent using a mildly acidic aqueous phase. The solvent contains the calixarene along with the modifier Cs-7SB in Isopar ${ }^{\circledR} \mathrm{L}$, two major components of the CSSX solvent. This approach is being taken to work towards a combined extraction of cesium and strontium. The derivative containing a benzyloxy group in the para position was found to be the best extractant. One gram of this compound was obtained from the university of Parma.

Actinide extraction was tested from a simulant of the SRS waste, but it was observed that some of the actinides (uranium, plutonium) precipitated out of the solution. Simpler solutions containing sodium carbonate, sodium hydroxide, and sodium nitrate were prepared, and the stability of the actinides of interest $(\mathrm{U}, \mathrm{Np}, \mathrm{Pu})$ was greatly improved. The diluent chosen for these extraction experiments is 1-octanol. A modified aliphatic diluent could also be considered, providing that the solubility of the terephthalamides is not compromised. New actinide extractants have been synthesized and tested, but so far the n-octyl terephthalamide exhibits the best behavior. Neptunium has been rigorously tested. Uranium and plutonium will be tested in the very near future.

\section{Planned Activities}

In the next year, we will investigate thoroughly the behavior of the calix[8]arenes octaamides and will try to understand their strontium extraction behavior when used in caustic media. Several other derivatives, modified mostly to enhance solubility, will be received in small quantities from the university of Parma. We are planning to reach a level of understanding high enough to test these compounds in batch tests with real wastes by the middle of September 2003. Regarding the actinide extraction, emphasis will be put on the extraction of plutonium, as it has been determined by SRS personnel as one of the main radioelements to extract from the waste. We will try to determine whether the oxidation state the plutonium is originally in (in the acidic stock solution) has an impact on its oxidation state in the caustic simulant. Work will be carried out in close collaboration with the UC Berkeley group to try to design the best extractants possible, robust to oxidation and caustic degradation. Tests will be carried out with uranium, neptunium, and plutonium, possibly with americium if the need is expressed by SRS.

\section{Information Access}

Research progress presented at the EMSP workshop in Richland, WA on May 7, 2003: Lætitia H. Delmau (PI), Kenneth N. Raymond (PI), and David Hobbs (PI): Combined Extraction of Cesium, Strontium, and Actinides for Alkaline Media: An Extension of the Caustic-Side Solvent Extraction (CSSX) Process Technology.

Oral presentation given at the $27^{\text {th }}$ Actinide Separations Conference held at Argonne National 
Laboratory Argonne, IL, on June 11, 2003:

Lætitia H. Delmau, Tamara J. Haverlock, Debbie A. Bostick, Alessandro Casnati, Rocco Ungaro, Kenneth N. Raymond, Jide $\mathrm{Xu}$, and Bruce A. Moyer, Extraction of Strontium and Actinides from Caustic Media: Fundamental Studies Towards the Extension of the CSSX Process.

List of publications or presentations relevant to this project are posted on the www home page of the ORNL Chemical Separations Group: http://www.ornl.gov/csg. 